\title{
ASSOCIATION OF SEROPOSITIVITY FOR CMV IGM AND IGG WITH ADVERSE PREGNANCY OUTCOME
}

\author{
Ambreen Amna, Farkhunda Nadeem, Amin Fahim, Altaf Hussian Jatoi*, Kanwal Abbas**, Sumayya Anas*** \\ Isra University Hospital, Hyderabad Pakistan, *Mohammadi Medical College, Mirpukhas Pakistan, **Liaquat University of Medical \& Sciences, Jamshora \\ Pakistan, ***Isra University, Karachi Pakistan
}

\begin{abstract}
Objective: To find out the prevalence of antibodies against cytomegalovirus and their association with adverse pregnancy outcome in women, at Isra University Hospital Hyderabad.

Study Design: Cross-sectional study.

Place and Duration of Study: Department of Gynaecology \& Obstetrics, Isra University Hospital (IUH) Hyderabad, from Jan to Jun 2018.

Methodology: Cytomegalovirus IgM and IgG antibodies in 305 women of reproductive age group were measured using the Enzyme Linked Fluorescent Assaysystem kit.

Results: The combined positivity of anti cytomegalovirus IgG and IgM antibodies was 93 (30.40\%). About 37 (37.37\%) and $28(34.14 \%)$ women were found to be seropositive for cytomegalovirus antibodies who had history of spontaneous miscarriage and recurrent miscarriages respectively.

Conclusion: Higher association of seropositivity for cytomegalovirus IgM and IgG with bad obstetrical history and low economy was found.
\end{abstract}

Keywords: Adverse pregnancy outcome, Cytomegalovirus, Intrauterine fetal death, Preterm labour.

This is an Open Access article distributed under the terms of the Creative Commons Attribution License (https://creativecommons.org/licenses/by-nc/4.0/), which permits unrestricted use, distribution, and reproduction in any medium, provided the original work is properly cited.

\section{INTRODUCTION}

Human cytomegalovirus (CMV) is an enveloped DNA virus of herpes family which is predominant universally in all socioeconomics classes ${ }^{1}$. Seropervalence of CMV is varies between $50-85 \%$ in developed world and around $100 \%$ in poorly developed countries$^{2}$. In a review, Griffith has stated that cytomegalovirus is the most frequent cause of intrauterine infection however it is occasionally blamed as an occupational hazard in working women of reproductive age group ${ }^{3}$.

CMV is responsible for most of the adverse early pregnancy complications like spontaneous or recurrent miscarriages and certain congenital malformations as well as it has also been isolated in women who had a history of still birth ${ }^{4}$. The birth prevalence of congenital cytomegalovirus infection is estimated at $0.64 \%$ and $11 \%$ of these infants are symptomatic ${ }^{5}$. CMV is mostly transmitted to the growing fetus during pregnancy as well as when come in direct close contact with young children who have acquired active infection. The rate of transmission of primary infection is high as compared to secondary infection'.

In the developed countries the major risk factor

Correspondence: Dr Farkhunda Nadeem, Department of Pathology, Isra University Hospital, Hyderabad Pakistan

Received: 25 May 2019; revised received: 09 Feb 2020; accepted: 10 Feb 2020 for the congenital infection is reported to be related with maternal primary CMV infection during pregnancy. Several researches have been carried out worldwide based on fetal congenital malformations resulting after CMV exposure6,7. However little literature is available about the women with bad obstetrical outcome and its relationship with CMV seroprevalence. The present study was conducted to find out the prevalence of antibodies against cytomegalovirus and their association with adverse pregnancy outcome in women, at Isra University Hospital Hyderabad.

\section{METHODOLOGY}

The present descriptive cross-sectional study was conducted from January to June 2018 at Isra University Hospital (IUH) Hyderabad. A total of 305 women in reproductive age group who had adverse pregnancy outcome visiting to clinic for complaints were enrolled. All the women were counseled and informed verbal consent was obtained for the study. Detailed history was taken regarding socio-demographic profile and adverse pregnancy out comes were further explored. Adverse pregnancy outcome is defined as unfavorable pregnancy outcome found as consecutive spontaneous miscarriages, intrauterine death, intrauterine growth restriction, stillbirth, early neonatal death and congenital anomalies. However women who had medical, genetic, autoimmune and positivity of other TORCH infections has been excluded from the 
study. The women participating in this study were all healthy women with past bad obstetrical event of not more than of six month duration. The study was approved by the Ethical Committee of Isra University Hospital (IUH). The participants were briefed regarding CMV infections and related possible complications.

A $5 \mathrm{ml}$ venous blood sample was taken from each woman and was submitted to the microbiology laboratory of IUH for anti CMV IgG and IgM antibodies analysis. The sera were separated and stored at $40 \mathrm{C}$ until analyzed. The anti CMV IgG and IgM antibodies against CMV were detected by using ELISA technique according to the instructions of the manufacture. The cut off values by the manufactures were used to determine the results. Mean \pm age, percentages and frequencies were calculatedfor the data and chi-square test was applied. SPSS-21 was applied for the statistical analysis.

\section{RESULTS}

A total 305 women were recruited with adverse pregnancy outcome and their association with CMV antibodies IgG and IgM were assessed. The mean age of study participant in current study was $29 \pm 18$ years (minimum 17 years, maximum 40 years). Anti CMV IgG/IgM antibodies were found in 93 (30.49\%) women, however $212(69.50 \%)$ women were found to be seronegative for CMV antibodies. The positivity for anti CMV IgG antibodies were found in 77 (82.79\%) while $16(17.20 \%)$ were found to be positive for anti CMV IgM antibodies. who are well educated and self employed as shown in table-I.

There is higher association of seropositivity for CMV IgM and IgG with bad obstetrical performance. About 37 (37.37\%) women were found to be seroposi-

Table-I: General characteristic of women $(n=305)$ with adverse pregnancy outcome and association with seropositivity for cytomegalovirus (IgM and IgG antibodies).

\begin{tabular}{|c|c|c|c|}
\hline $\begin{array}{l}\text { General } \\
\text { Characteristic of } \\
\text { study Participants }\end{array}$ & $\begin{array}{c}\text { No. of } \\
\text { cases }(\%)\end{array}$ & $\begin{array}{l}\text { Seropositivity } \\
\text { for IgG and } \\
\text { IgM }\end{array}$ & $\begin{array}{c}p \text { - } \\
\text { value }\end{array}$ \\
\hline \multicolumn{4}{|l|}{ Age } \\
\hline$<40$ years & $162(53.11)$ & $60(37.03 \%)$ & \multirow{2}{*}{0.04} \\
\hline$>40$ years & $143(46.88)$ & $33(23.07 \%)$ & \\
\hline \multicolumn{4}{|l|}{ Parity } \\
\hline Primipara ${ }^{1}$ & $108(35.40)$ & $19(17.59 \%)$ & \multirow{3}{*}{0.05} \\
\hline Multipara $^{2}$ & $153(50.16)$ & $31(20.26 \%)$ & \\
\hline Grand Multi para ${ }^{3}$ & $44(14.42)$ & $43(97.72 \%)$ & \\
\hline \multicolumn{4}{|l|}{ Educational Level } \\
\hline Low $^{4}$ & $217(71.14)$ & $59(27.18 \%)$ & \multirow{2}{*}{0.05} \\
\hline High $^{5}$ & $88(28.85)$ & $34(38.63 \%)$ & \\
\hline \multicolumn{4}{|c|}{ Socioeconomic Status (SES) } \\
\hline$<10,000$ PKR & $197(64.59)$ & $69(35.02 \%)$ & \multirow{3}{*}{0.03} \\
\hline 10,000-15000 PKR & $61(20)$ & $15(24.59 \%)$ & \\
\hline$>15000$ PKR & $47(15.40)$ & $9(19.14 \%)$ & \\
\hline
\end{tabular}

tive for CMV IgG antibodies and IgM antibodies who had history of spontaneous miscarriage, whereas 28 $(34.14 \%)$ for recurrent miscarriages were seropositive for IgG and IgM antibodies shown in table-II.

Legends

1. Primipara: having given birth to only one child

Table-II: Association of seropositivity for cytomegalovirus (IgM and IgG antibodies) with adverse pregnancy outcome in 305 participating women.

\begin{tabular}{|c|c|c|c|c|}
\hline \multirow{2}{*}{$\begin{array}{l}\text { Variables of Adverse } \\
\text { pregnancy outcome }\end{array}$} & \multirow[b]{2}{*}{$\begin{array}{l}\text { No. of cases } \\
\quad(n=305)\end{array}$} & \multicolumn{2}{|c|}{ Seropositivity for CMV antibodies } & \multirow[b]{2}{*}{$p$-value } \\
\hline & & $\begin{array}{l}\text { Seropositivity for } \\
\text { IgG }(n=77)\end{array}$ & $\begin{array}{l}\text { Seropositivity for IgM } \\
(\mathrm{n}=16)\end{array}$ & \\
\hline Spontaneous Miscarriages ${ }^{1}$ & 99 & $29(29.29 \%)$ & $8(8.08 \%)$ & 0.04 \\
\hline Recurrent Miscarriage ${ }^{2}$ & 82 & $23(28.04 \%)$ & $5(6.09 \%)$ & 0.04 \\
\hline Still Born ${ }^{3}$ & 64 & $16(25 \%)$ & $1(1.56 \%)$ & 0.06 \\
\hline IUFD 4 & 21 & $5(23.80 \%)$ & $1(4.76 \%)$ & 0.06 \\
\hline Preterm labour ${ }^{5}$ & 13 & $1(7.69 \%)$ & - & 0.08 \\
\hline IUGR $^{6}$ & 17 & $2(11.76 \%)$ & - & 0.07 \\
\hline $\mathrm{ENND}^{7}$ & 9 & $1(11.11 \%)$ & $1(11.11 \%)$ & 0.07 \\
\hline
\end{tabular}

There were significant difference between the CMV IgG/IgM with sociodemographic profile based on age, parity, literacy rate and employment status $(p<0.05)$. The women who were unemployed with poor socioeconomic back ground and have more children showed higher IgG and IgM level compared to those
2. Multipara: having more than one children

3. Grand multi para: condition of having given birth five or more times

4. Low education level: basic primary education only

5. High education level: higher secondary school education or above 


\section{Legends}

1. Spontaneous miscarriages (abortion): expulsion of products of conception before 20 weeks of gestation when the weight of fetus is 500 gram or less.

2. Recurrent miscarriage: occurrence of three or more consecutive pregnancy loss.

3. Still born: fetal death at or after 20th to 28th weeks gestation without sign of life. IUFD (intra uterine fetal death): fetal/infant death during delivery, which was not associated with improper management.

4. Preterm labour: labour resulting in birth before 37 completed weeks (259 days) of gestational age.

5. IUGR (intra uterine growth restriction): estimated fetal weight is at or below the 10th percentile of gestational age.

6. ENND (early neonatal death): death of a live born with in first seven days of delivery .

\section{DISCUSSION}

Human cytomegalovirus (HCMV) belongs to herpes virus family and is associated with persistent, latent and recurrent infection. In developed countries human cytomegalovirus (CMV) infection seroprevalence in pregnant women is reported to be around 42$68 \%$ whereas over $95 \%$ in developing countries such as China ${ }^{8}$. Besides this, the prevalence of live birth in congenital CMV infection in the developed world is only $0.6-0.7 \%$. Women affected with this virus during pregnancy are prone for miscarriages, stillbirth, birth defects and also puts hazard to attending nursing staff 9 .

It was found in present study that out of 305 study participants, 93 women (30.49\%) showed seropositivity for CMV IgG/IgM antibodies. Similarly Sadik et al conducted a study in women with bad obstetrical history in south Indian population. He reported presence of IgM and IgG antibodies for CMV in $23.25 \%$ of randomly selected 86 pregnant women ${ }^{10}$.

In present study most of the seropositive women, showed positivity for IgG antibody against CMV 77 $(82.79 \%)$ while only $16(17.20 \%)$ were seropositive for IgM antibody. Reason for high prevalence of IgG antibody may be due to random collection of data from non-pregnant women, whereas the infection might be acquired during pregnancy. Similarly Wang et al in his study conducted on seroprevalence of cytomegalo virus among women of reproductive age in the United States reported that out of 5714 women included in the analysis, majority of participants $(70 \%)$ were $\operatorname{IgG}$ +ve ${ }^{11}$.

Present study revealed that out of 305 study participants, 162 (53.11\%) were of less than 40 years of age and out of these i.e., $60(37 \%)$ were seropositive for IgG/IgM against CMV. On the other hand 143 $(46.88 \%)$ of women were $>40$ years of age and out of these $33(23.07 \%)$ showed seropositivity for the same antibodies. Similarly Staras et al in his study conducted in the United States reported CMV seroprevalence of $58.3 \%$ among women of childbearing age i.e., 15-44 years ${ }^{12}$. These results signify the prevalence of CMV infection in reproductive age group.

Household income level was found to be inversely associated with CMV seroprevalence in present study. It was found that of 197 (64.59\%) participant having low level of income, 69 (35.02\%) were CMV seropositive. Whereas 15 (24.59\%) from the middle level and 9 (19.14\%) from high level of income showed seropositivity for CMV. These results are quite significant as they show that majority of the participants were having low level of income and although the percentage of seropositive women was 35.02 but it make $74.19 \%$ of the total 93 seropositive cases which reflect high prevalence of CMV in women of low socioeconomic group. Similar results were reported by Staras et al who found $70.8 \%$ seropositivity for CMV in the women with low income and $60.5 \%$ and $46.6 \%$ in women with middle and high income respectively ${ }^{12}$.

Comparable results were reported by Enders et al who concluded about the association of CMV with socioeconomic status, as CMV seroprevalence in low, middle and upper socioeconomic status was $91.8 \%$, $46.9 \%$ and $33.7 \%$, respectively ${ }^{13}$. Supporting the findings Bate et al in 2010 reported low socioeconomic status as a strong risk factor for acquiring CMV infection $^{14}$.

Present study reveals that of 305 participants, 217 $(71.14 \%)$ had received primary education while 88 (28.85\%) had reached to the senior high school level. Of these, $59(27.18 \%)$ of 217 women with low education level and $34(38.63 \%)$ women with comparatively high education were showing seropositivity. These results reflect the positive relationship between the occurrence of CMV infection and low education level. Regarding the parity, the results revealed that majority of seropositive women i.e., $43(97.72 \%)$ were grand multi para followed by multipara $31(20.26 \%)$. On the other hand only $19(17.59 \%)$ of the total primary para women were seropositive. More or less same results 
were reported by Hamdan et al who concluded in their study that uneducated women and those having high parity were at increased risk for acquiring infection with CMV. They have reported 46.7\%, 41.9\%, 10.2\% and $1.2 \%$ seropositivity in women who were Illiterate, received primary, secondary and university level education respectively ${ }^{15}$. The above mentioned factors were also reported as risk factors CMV infection in some other studies as well. The authors have concluded that the increased CMV prevalence in these groups may be due to close contact between family members and poor hygiene responsible for transferring contagious secretions ${ }^{14,16}$.

Present study also evaluated the relationship between prevalence of infection with CMV and spontaneous abortion. These results revealed that out of 305 participating women, $99(32.45 \%)$ had spontaneous abortion of their last pregnancy. Of these 29 (29.29\%) women showed seropositivity for IgG against CMV, 8 $(8.08 \%)$ for IgM. Further, the results also showed that 82 of total study participants were having history of recurrent miscarriage, out of which $23(28.04 \%)$ were showing presence of IgG type of antibodies, while 5 $(6.09 \%)$ were having IgM antibodies against CMV. These results showed a significant correlation of CMV infection during pregnancy with spontaneous and recurrent abortion. The results are comparable to the results reported by Jasim et al, who stated that out of 300 women having bad obstetrical history, 162 women were presented with history of spontaneous abortion and of these, $60.2 \%$ women revealed presence of IgM antibodies against CMV in their sera. He further reported that high percentage $(12.4 \%)$ of repeated abortions was seen in women showing seropositivity for $\mathrm{CMV}^{\mathrm{IgM}}{ }^{17}$. Another study conducted at Al-Diwaniyah on 125 women for evaluation of the sero-prevalence of cytomegalovirus and toxoplasmosis had reported highest prevalence of CMV infection in the first trimester in women with history of multiple abortions for both pathogens ${ }^{18}$.

The results of the present study also showed that in women who presented with history of stillbirth of one or more of her children, $16(25 \%)$ and 1 (1.56\%) women showed seropositivity for IgG and IgM antibodies respectively at the time of evaluation in nonpregnant state. More or less same results have been documented by Howard et al who has reported that intrauterine deaths including stillbirths may be caused by CMV infection as $10(9 \%)$ stillborn infants were CMV positive out of total of 107 infants in his study ${ }^{19}$.
Likewise, another study conducted by Iwasenko et al regarding CMV and its role in stillbirths, done on placenta and fetal tissue from a series of 130 stillborn infants has reported presence of DNA of CMV in $15 \%$ of specimens. This is again in favour of the results of present study and show strong association and a possible etiological role of CMV with bad pregnancy outcome $^{20}$. Same type of study was conducted by Padmavathy et al in 2013 on the association of TORCH infections with bad pregnancy outcome. The author reported the CMV IgM and IgG positivity as $9.2 \%$ and $95.4 \%$ respectively ${ }^{21}$.

The results of present study also indicate that 21 of study participants (out of 305) were having history of intra uterine death of their last baby. Out of these, $5(23.80 \%)$ women were showing seropositivity for IgG antibody, while only one woman was having IgM antibodies. Comparatively lesser number $8.4 \%$ cases with history of intrauterine fetal deaths were reported by Padmavathy ${ }^{21}$.

The results also signify that 17 of total study participants were presented with history of IUGR of their last baby. Out of these $2(11.76 \%)$ were found to have IgG antibody. These results are also quite significant as they show that some of the cases of IUGR were due to infection by CMV. Hendrix has put into same words in a seminar in Perinatology as fetal infections are responsible for up to $10 \%$ of growth restriction cases and presently the most common causes are toxoplasmosis and cytomegalovirus in developed countries $^{22}$. Similarly Bamberg $\mathrm{C}$ has narrated about the causes of IUGR in a seminar in fetal and neonatal medicine as "congenital infection by CMV during early gestational time is important beside familial lesions leading togenetic anomalies" 23 .

In addition to other bad pregnancy outcomes, CMV also has effects of preterm labour. In present study, it was found that out of 305 study women, 13 were presented with history of preterm labour in their last pregnancy. It was noted that out of these $7.69 \%$ were showing presence of IgG type of antibodies against CMV. Romero et al has focused on effects of inflammatory reactions on fetal injury and pre term parturition in a seminar on Fetal and Neonatal Medicine. He has stated that inflammation/Infection is a frequent and important mechanism of disease in PTL and delivery and CMV is one of the most important causes $^{24}$.

The results of present study also reflect the important association of CMV infection during preg- 
nancy and its effects on fetus in early neonatal period. It shows that out of 305 study participants, 9 women presented with history of early neonatal death of their last baby and out of these; $11.11 \%$ were showing presence of IgG antibody while same percentage were showing presence of IgM type of antibody against CMV. Boppana has reported a study on 106 neonate with symptomatic congenital CMV infection and has concluded that neonate with symptomatic congenital CMV infection suffer from multisystem diseases with significant morbidity and mortality as $12 \%$ of infants died during the first week of life ${ }^{25}$.

\section{CONCLUSION}

It can be concluded from the results of the present study that bad pregnancy outcome is common in region of Hyderabad and its peripheral areas and CMV is one of the important causes. The women in this area are not aware of this, hence it seems to be more common in women with low education level and low socioeconomic status. Moreover, CMV infection during pregnancy is responsible for a considerable number of cases of spontaneous and recurrent miscarriages, still birth, IUFD, preterm labour, IUGR and ENND.

\section{CONFLICT OF INTEREST}

This study has no conflict of interest to be declared by any author.

\section{REFERENCES}

1. Walker SP, Palma-Dias R, Wood EM, Shekleton P, Giles ML. Cytomegalovirus in pregnancy: to screen or not to screen. BMC Pregnancy Childbirth 2013; 18(13): 96.

2. Zuckerman AJ, Banatvala JE, Pattison JR, Griffiths PD, Schoub BD. Cytomegalovirus (In: Principles and Practice of Clinical Virology, Fifth Edition, John Wiley and Sons, Ltd., West Suusex, England 2004; 85: 122.

3. Gargouri J. Elleuch H, Karray H, Reik H, Hammami A. Prevalence of anti CMV antibodies in blood donars in the stax region (value in blood transfusion)[French]. Tunis Med 2000; 78: 512-17.

4. Cannon MJ. Congenital cytomegalovirus (CMV) epidemiology and awareness. J ClinVirol 2009; 46: S6-10.

5. Iwasenko JM, Howard J, Arbuckle S, Graf N, Hall B, Craig ME, et al. Human cytomegalovirus infection is detected frequently in stillbirths and is associated with fetal thrombotic vasculopathy. J Infect Dis 2011; 203(11): 1526-33.

6. Kenneson A, Cannon MJ. Review and meta analysis of the epidemiology of congenital cytomegalovirus (CMV) infection. Rev Med Virol 2007; 17(4): 253-76.

7. Enders G, Daiminger A, Ba"der U, Exler S, Schimpf Y, et al. The value of CMV IgG avidity and immunoblot for timing the onset of primary CMV infection in pregnancy. J ClinVirol 2013; 56(1): 102-107.
8. Yamamoto AY, Castellucci RA, Aragon DC, Mussi-Pinhata MM. Early high CMV seroprevalence in pregnant women from a population with a highrate of congenital infection. Epidemiol Infect 2013; 141: 2187-91.

9. Kenneson A, Cannon MJ. Review and meta-analysis of the epidemiology of congenital cytomegalovirus (CMV) infection, Rev Med Virol 2007; 17: 253-76.

10. Sadik MS, Fatima H, Jamil K, Patil C. Study of TORCH profile in patients with bad obstetric history. Biology Medicine 2012; 4(2): 95.

11. Wang C, Dollard SC, Amin MM, Bialek SR. Cytomegalovirus IgM seroprevalence among women of reproductive age in the United States. PloS one 2016; 11(3): e0151996.

12. Staras SA, Dollard SC, Radford KW, Flanders WD, Pass RF, Cannon MJ. Seroprevalence of cytomegalovirus infection in the United States, 1988-1994. Clin Infec Dis 2006; 43(9): 1143-51.

13. Enders G, Daiminger A, Lindemann L, Knotek F, Bäder U, Exler $\mathrm{S}$, et al. Cytomegalovirus (CMV) seroprevalence in pregnant women, bone marrow donors and adolescents in Germany, 19962010. Med Microbiol Immunol 2012; 201(3): 303-09.

14. Bate SL, Dollard SC, Cannon MJ. Cytomegalovirus seroprevalence in the United States: the national health and nutrition examination surveys, 1988- 2004. Clin Infect Dis 2010; 50(11): 1439-47.

15. Hamdan HZ, Abdelbagi IE, Nasser NM, Adam I. Seroprevalence of cytomegalovirus and rubella among pregnant women in western Sudan. Virol J 2011; 8(1): 217.

16. Kramer A, Schwebke I, Kampf G. How long do nosocomial pathogens persist on inanimate surfaces? A systematic review. BMC Infect Dis 2006; 6: 130.

17. Jasim M, Majeed HA, Ali AI. Performance of Serological Diagnosis of TORCH Agents in Aborted versus non aborted Women of Waset province in Iraq. Tikrit Med J 2011; 17(2): 141-47.

18. Al-Shimmery MN, Al-Hilaly HA, Al-Khafaji AA. Seroprevalence of cytomegalovirus and toxoplasmosis in cases of miscarriages women in Al-Diwaniyah province. Al-Qadisiah Med J 2011; 7(1): $160-68$.

19. Howard J, Hall B, Brennan LE, Arbuckle S, Craig ME, Graf N, et al. Utility of newborn screening cards for detecting CMV infection in cases of stillbirth. J Clinic Virol 2009; 44(3): 215-18.

20. Iwasenko JM, Howard J, Arbuckle S, Graf N, Hall B, Craig ME, et al. Human cytomegalovirus infection is detected frequently in stillbirths and is associated with fetal thrombotic vasculopathy. J Infec Disease 2011; 203(11): 1526-33.

21. Padmavathy M, Mangala G, Malini J, Umapathy BL, Navaneeth $\mathrm{BV}$, Bhatia $\mathrm{M}$, et al. Seroprevalence of TORCH infections and adverse reproductive outcome in current pregnancy with bad obstetric history. J Clin Biomed Sci 2013; 3(2): 62-71.

22. Hendrix N. Non-placental causes of intrauterine growth restriction. In Seminars in perinatology 2008; 32(3): 161-65.

23. Bamberg C, Kalache KD. Prenatal diagnosis of fetal growth restriction. In Seminars in Fetal and Neonatal Medicine 2004; 9(5): 387-94.

24. Romero R, Espinoza J, Gonçalves LF, Kusanovic JP, Friel LA, Nien JK. Inflammation in preterm and term labour and delivery. In Seminars in Fetal and Neonatal Medicine 2006;11(5): 317-326.

25. Boppana SB, Pass RF, Britt WJ, Stagno S, Alford CA. Symptomatic congenital cytomegalovirus infection: neonatal morbidity and mortality. Pediatr Infect Dis J 1992; 11(2): 93-98. 